\title{
Upregulation of the long noncoding RNA UBOX5 antisense RNA 1 (UBOX5-AS1) under hypoxic conditions promotes epithelial-mesenchymal transition in endometriosis
}

\author{
Hengwei Liu ${ }^{1 \#}$, Haitang $\mathrm{He}^{2 \#}$, Zhibing Zhang ${ }^{3,4}$, Lili Wang ${ }^{5}$, Ling Zhang ${ }^{2}$, Yi Liu ${ }^{2}$, Wenqian Xiong ${ }^{2}$ \\ ${ }^{1}$ Department of Obstetrics and Gynecology, Zhongnan Hospital of Wuhan University, Wuhan University, Wuhan, China; ${ }^{2}$ Department of Obstetrics \\ and Gynecology, Union Hospital, Tongji Medical College, Huazhong University of Science and Technology, Wuhan, China; ${ }^{3}$ Department of \\ Physiology, Wayne State University, Detroit, MI, USA; ${ }^{4}$ Department of Obstetrics and Gynecology, Wayne State University, Detroit, MI, USA; \\ ${ }^{5}$ Department of Obstetrics and Gynecology, Wuhan Pu-Ai Hospital, Tongji Medical College, Huazhong University of Science and Technology, \\ Wuhan, China \\ Contributions: (I) Conception and design: Y Liu, W Xiong; (II) Administrative support: Z Zhang, L Zhang; (III) Provision of study materials or \\ patients: Y Liu, W Xiong; (IV) Collection and assembly of data: H Liu, H He; (V) Data analysis and interpretation: H Liu, H He, L Zhang, L Wang; \\ (VI) Manuscript writing: All authors; (VII) Final approval of manuscript: All authors. \\ "These authors contributed equally to this work and are joint first authors. \\ Correspondence to: Yi Liu. Department of Obstetrics and Gynecology, Union Hospital, Tongji Medical College, Huazhong University of Science and \\ Technology, Wuhan 430022, China. Email: liqun1994@hust.edu.cn; Wenqian Xiong. Department of Obstetrics and Gynecology, Union Hospital, \\ Tongji Medical College, Huazhong University of Science and Technology, Wuhan 430022, China. Email: 176051948@qq.com.
}

Background: Endometriosis is a debilitating gynecological condition that manifests many common malignant features, including migration and invasion. Hypoxia is a hallmark of endometriosis, characterized by endometrial cell metastasis via epithelial-mesenchymal transition (EMT). The long noncoding RNA (lncRNA) UBOX antisense RNA 1 (UBOX5-AS1) has been shown to be upregulated in ovarian endometriosis. However, the molecular mechanisms and biological functions of lncRNA UBOX5-AS1 in hypoxia-induced endometriosis EMT remain to be explored.

Methods: Normal, eutopic, and ectopic endometrium from ovarian endometriosis tissues were collected, and the expressions of hypoxia inducible factor (HIF)-1 $\alpha$, lncRNA UBOX5-AS1, E-cadherin, and vimentin were analyzed by quantitative real time polymerase chain reaction (qRT-PCR) and western blotting analysis. Primary human endometrial epithelial cells and human endometrial epithelial adenocarcinoma Ishikawa cell lines were cultured under hypoxic conditions, and western blotting analysis and immunocytochemistry were performed to investigate hypoxia-induced EMT. Moreover, HIF-1 $\alpha$ and lncRNA UBOX5-AS1 were overexpressed and knocked down in endometrial epithelial cells to explore the role and mechanisms of lncRNA UBOX5-AS1 in hypoxia-triggered EMT. The migration and invasion potential of human endometrial epithelial cells was detected by Transwell migration/invasion assays.

Results: In ovarian endometriosis, the expression of hypoxia-inducible factor- $1 \alpha(H I F-1 \alpha)$ and lncRNA UBOX5-AS1 were significantly increased, and this was accompanied by EMT. Furthermore, endometrial epithelial cells cultured under hypoxic conditions exhibited elevated lncRNA UBOX5-AS1 expression, as well as migration, invasion, and an EMT-like phenotype. This data indicated that $H I F-1 \alpha$ signaling was crucial for hypoxia-induced lncRNA UBOX5-AS1 upregulation and the EMT process. Moreover, downregulation of lncRNA UBOX5-AS1 inhibited the hypoxia-induced EMT and attenuated cell migration and invasion.

Conclusions: The present research demonstrated that hypoxia upregulated the expression of lncRNA UBOX5-AS1 via HIF-1 $\alpha$-dependent signaling. The increased expression of lncRNA UBOX5-AS1 plays a vital role in mediating the hypoxia-regulated EMT and invasiveness of endometriosis, suggesting that lncRNA UBOX5-AS1 may be an important potential therapeutic target for endometriosis. 
Keywords: Hypoxia; hypoxia-inducible factor- $1 \alpha(H I F-1 \alpha)$; long noncoding RNA UBOX antisense RNA 1 (lncRNA-UBOX5-AS1); epithelial-mesenchymal transition (EMT); endometriosis

Submitted Jun 07, 2020. Accepted for publication Jan 22, 2021.

doi: 10.21037/atm-20-4546

View this article at: http://dx.doi.org/10.21037/atm-20-4546

\section{Introduction}

Endometriosis is a common gynecological condition defined by the presence of ectopic endometrial tissue outside the uterine cavity (1). Over the last few decades, extensive investigations have been conducted to identify the pathogenesis of endometriosis, but the precise etiology still remains poorly understood (2). Sampson's retrograde menstruation/transplantation theory proposes that during menstruation, the fragments of viable endometrial tissue that are shed could be refluxed into the abdominal cavity via the fallopian tubes and subsequently implanted into ectopic locations (3). However, even though retrograde menstruation can occur to some degree in a majority of women, only $5-10 \%$ develop endometriosis. This suggests that other factors may be involved in the formation of endometriotic lesions. Several studies have hypothesized that an altered peritoneal hypoxic microenvironment may play a causative role in the pathogenesis of endometriosis (4).

Hypoxia is a vital microenvironmental factor that contributes to the pathogenesis of endometriosis $(5,6)$. We have previously reported that hypoxia-inducible factor- $1 \alpha$ $(H I F-1 \alpha)$, the key regulator that mediates cellular hypoxic responses, is elevated in ectopic endometriotic tissues (7). Upregulation of the $H I F-1 \alpha$ gene increases the activation of numerous downstream genes which are involved in the regulation of multiple vital biological events, such as apoptosis, proliferation, migration, invasion, and epithelialmesenchymal transition (EMT) (8-10).

Recent studies have attributed EMT to the development and progression of human endometriosis $(11,12)$. EMT is a well-known physiological process related to the initiation of cell migration, invasion, and metastasis (13). During this process, epithelial cells display loss of cellular apicobasal polarity and intercell adhesion, and gradually acquire invasive features to become mesenchymal-like cells. This process is highly modulated by many signaling pathways, including hypoxia-related signaling pathways and cytokines such as transforming growth factor (TGF)- $\beta 1$ (14). Moreover, the activity of many EMT transcriptional regulators such as Twist1, Snail, zinc finger E-box-binding homeobox 1 (ZEB1), and $\beta$-catenin, are regulated either directly or indirectly by hypoxia $(15,16)$. Previous reports demonstrated that EMT participates in the pathogenesis of endometriosis $(11,17)$. Moreover, hypoxia may also trigger the EMT process in multiple cancer cells $(18,19)$. However, the critical cellular molecular mechanisms underlying the pathogenesis of the hypoxia/ HIF- $\alpha$-triggered EMT process in endometriosis remain unknown.

Long noncoding RNAs (lncRNAs), defined by their length of more than 200 nucleotides, are a group of RNA molecules that lack protein-coding capacity $(20,21)$. Previous studies have demonstrated that lncRNAs can be regulated under hypoxia in cancer cells (22). In addition, IncRNAs play a vital role in the regulation of the EMT process (23). LncRNAs are dysregulated in a number of gynecological diseases, including cervical cancer, endometrial carcinoma, and endometriosis $(24,25)$. Recently, 1682 dysregulated lncRNAs were identified in ovarian endometriosis using the human transcriptome array. One of these dysregulated lncRNAs is UBOX 5 antisense RNA 1 or UBOX5-AS1 (chromosome 20: 3,106,913-3,150,867/ NR_038395) located at 20p13. UBOX5-AS1 was initially discovered and investigated in ovarian endometriosis tissues, and identified as a potential noninvasive biomarker for ovarian endometriosis (26). As peritoneal hypoxia is also a unique characteristic of the microenvironment in ovarian endometriosis, this study aimed to determine whether overexpression of IncRNA-UBOX5AS1 in ovarian endometriosis is induced by the hypoxic microenvironment and whether lncRNA-UBOX5-AS1 contributes to the hypoxia/HIF-1 $\alpha$-triggered EMT process in endometriosis.

This study explored the expression patterns and function of UBOX5-AS1 in hypoxic endometrial epithelial cells and demonstrated that UBOX5-AS1 was activated by hypoxia via the HIF-1 $\alpha$ signaling pathway. Hypoxia-induced expression of UBOX5-AS1 promoted the invasion and EMT of endometrial epithelial cells. These data form a basis for further investigations into the molecular mechanisms of how hypoxia contributes to EMT and the invasion of endometriosis, as well as and the involvement of UBOX5- 
AS1 under hypoxic conditions. We present the following article in accordance with the MDAR reporting checklist (available at http://dx.doi.org/10.21037/atm-20-4546).

\section{Methods}

\section{Materials}

Monoclonal anti-HIF-1 $\alpha$ antibody (RRID:AB_2835328) was purchased from Affinity (USA), monoclonal anti-Ecadherin (RRID:AB_731493) and anti- $\beta$-actin antibodies (RRID:AB_306371) were obtained from Abcam (UK), and monoclonal anti-vimentin antibody (RRID:AB_10695459) was purchased from Cell Signaling Technology (CST, USA). Secondary anti-rabbit immunoglobin G (IgG) antibodies were obtained from Santa Cruz (USA). Neofect ${ }^{\mathrm{TM}}$ DNA transfection reagent was purchased from Neofect Biotechnologies (China). T-25- $\mathrm{cm}^{2}$ flasks for cell culture were purchased from Bever (USA) and Transwell inserts for 24-well plates $(6.5 \mathrm{~mm}$ diameters and $8.0 \mu \mathrm{m}$ diameter filters) were purchased from Corning (USA). Sealed hypoxia incubator chambers were obtained from Thermo Fisher Scientific (USA). Other chemicals of analytical grade were obtained from Sigma-Aldrich (USA).

\section{Patients and tissue collection}

The study was conducted in accordance with the Declaration of Helsinki (as revised in 2013) and approved by the local Ethics Committee of Tongji Medical College, Huazhong University of Science (No. IORG0003571). The participants were recruited at the Obstetrics and Gynecology Department, Union Hospital, Tongji Medical College, Huazhong University of Science and Technology, and signed informed consent was obtained from all patients. A total of 10 cases of eutopic endometrium and 9 cases of ectopic endometrium from patients with ovarian endometriosis were collected. As controls, 11 cases of normal endometrium specimens were collected from healthy women who underwent tubal sterilization and were laparoscopically confirmed to be free of endometriosis. A further 70 cases of normal healthy endometrium were collected for the isolation of primary human endometrial epithelial cells.

The recruited women displayed normal menstrual cycles (range, 22-33 days), and none of the patients received any anti-inflammatory or hormonal treatments within 3 months prior to the surgery. At the time of biopsy collection, all participants were in the proliferative phase of the menstrual cycle, as confirmed by clinical or histological criteria. The stage of ovarian endometriotic tissues was confirmed according to the classification of the American Society for Reproductive Medicine (27). All fresh specimens were snap frozen and immediately stored in liquid nitrogen. Samples were used for RNA and protein extraction or paraffin embedding for immunohistochemistry. The clinical data of the patients are summarized in Table S1.

\section{Isolation and culture of primary buman endometrial epithelial cells and buman endometrial epithelial adenocarcinoma Ishikawa cell lines}

Human endometrial epithelial cells were isolated using methods previously described with slight modifications (28). Briefly, freshly collected normal endometrial tissues were washed with cold $1 \times$ sterile phosphate buffer saline (PBS) and cut into $1-2 \mathrm{~mm}^{3}$ pieces using sterile surgical scissors. The minced tissue was then incubated with $2 \mathrm{mg} / \mathrm{mL}$ type II collagenase (0.1\%, Sigma-Aldrich) in PBS for 1 hour at $37{ }^{\circ} \mathrm{C}$. After digestion, the suspension was filtered with a $150-\mu \mathrm{m}$ sterile sieve to remove residual tissue debris and followed by filtering with a $38-\mu \mathrm{m}$ sterile sieve to separate the human endometrial epithelial cells from the stromal cells. The epithelial cells were collected and resuspended in a 1:1 mixture of Dulbecco's modified Eagle's/F12 medium (DMEM/F12; HyClone) supplemented with $20 \%$ fetal calf serum (FCS; HyClone, USA), $100 \mathrm{U} / \mathrm{mL}$ penicillin, and $100 \mathrm{mg} / \mathrm{mL}$ streptomycin (HyClone). Cells were plated in 6-well culture plates. Cell immunofluorescence assay was performed to detect the purity of the cells. The purity of the cells was $>95 \%$, with no more than $1 \%$ stromal cell contamination.

Given that primary human endometrial epithelial cell can only be cultured for 2 passages and cannot be transfected, the human endometrial epithelial adenocarcinoma Ishikawa cell line (Shanghai Fuxiang Biotechnology Co., Ltd., China) was also used in this study. The Ishikawa cells were cultured in RMPI-1640 culture media (HyClone) supplemented with $10 \% \mathrm{FBS}, 100 \mathrm{U} / \mathrm{mL}$ penicillin and $100 \mathrm{mg} / \mathrm{mL}$ streptomycin (HyClone) in humidified atmosphere with $5 \%$ $\mathrm{CO}_{2}$ at $37^{\circ} \mathrm{C}$.

\section{Hypoxia treatment}

Cells were plated and cultured in normoxic conditions and grown to approximately $60-70 \%$ confluence. Cells were then incubated in a sealed incubator chamber in $1 \% \mathrm{O}_{2}, 5 \%$ 
$\mathrm{CO}_{2}$, and $94 \% \mathrm{~N}_{2}$ (Thermo Fisher Scientific) to simulate the hypoxic environment. The cells in the control group were incubated under normoxic cell culture conditions at $37{ }^{\circ} \mathrm{C}$ with $21 \% \mathrm{O}_{2}, 5 \% \mathrm{CO}_{2}$, for the indicated time periods.

\section{Identification of isolated human endometrial epithelial cells}

Immunofluorescence experiments were conducted to detect the epithelial protein E-cadherin and the mesenchymal protein vimentin. Cells were first plated and cultured on coverslips in 6-well plates and then washed 3 times with PBS and fixed with $10 \%$ neutral buffered formalin (NBF) for 0.5 hours at room temperature. Cells were permeabilized with $0.1 \%$ Triton X-100 (Sigma-Aldrich) at $4{ }^{\circ} \mathrm{C}$ for 0.5 hours, followed by incubation with $5 \%$ bovine serum albumin (BSA) for 1 hour at room temperature to block nonspecific binding. After washing with Tris buffered saline with Tween (TBST), cells were incubated with the appropriate antibody (E-cadherin and vimentin) overnight at $4{ }^{\circ} \mathrm{C}$. On the following day, cells were treated with a goat FITC-conjugated anti-rabbit IgG or a goat $\mathrm{Cy} 3$-conjugated anti-rabbit IgG for 2 hours, followed by DAPI staining for 15 minutes at room temperature. Cells were then washed 3 times with TBST and visualized under a confocal microscope (Olympus America Inc., USA). The isotypematched IgG from normal rabbits was used as a negative control (see Figure S1).

\section{$R N A$ extraction and quantitative real-time polymerase chain reaction}

Total RNA was extracted from endometrial biopsies and cells using Trizol reagent (TaKaRa Bio, Japan). RNA was reverse transcribed to cDNA using the PrimeScript ${ }^{\mathrm{TM}}$ RT reagent Kit With gDNA Eraser (TaKaRa Bio). The quantitative real-time polymerase chain reaction (qRT-PCR) was conducted using the Step-One-Plus-TM real-time PCR system (Applied Biosystems Inc, USA) with quantitative SYBR Green PCR kit (TaKaRa Bio). $\mathrm{C}_{t}$ values were automatically generated by the instrument's application software, and relative gene expression was examined by the $2^{-\Delta \Delta \mathrm{Ct}}$ method with glyceraldehyde 3 -phosphate dehydrogenase (GAPDH) as an internal control. The primers sequences used in qRT-PCR are shown in Table S2.

\section{Protein quantification by western blotting}

Total protein was extracted from human endometrial cells and endometrial tissues using RIPA buffer (Sigma Aldrich) containing protease inhibitors (Sigma Aldrich), and denatured at $95{ }^{\circ} \mathrm{C}$ for 10 minutes. Total proteins $(30 \mu \mathrm{g})$ were separated on a $12 \%$ sodium dodecyl-sulfate polyacrylamide gel electrophoresis (SDS-PAGE) gels and transferred onto polyvinylidene fluoride (PVDF) membranes. Membranes were then incubated in $5 \%$ nonfat milk in TBST containing $0.05 \%$ Tween-20 at room temperature for 1 hour. After blocking, the membrane was probed with the following primary antibodies at $4{ }^{\circ} \mathrm{C}$ overnight: $H I F-1 \alpha, \mathrm{E}$-cadherin, vimentin, and $\beta$-actin (diluted 1:3,000, Abcam,). After being washed 3 times with TBST, the membranes were incubated for 1 hour at room temperature with a goat anti-rabbit HRP secondary antibody (1:4,000; CST), or a secondary antibody conjugated to horseradish peroxidase (1:3,000; Santa Cruz,). Reactive bands were detected using the enhanced chemiluminescence (ECL) western blotting detection reagent (Millipore, USA), analyzed using an imaging system (Gel Doc 2000; BioRad, USA), and quantified using Image J software (National Institutes of Health, USA). Details of the antibodies used for western blotting analysis are listed in Table S3.

\section{Cell transfection}

The lncRNA-UBOX5-AS1 overexpression plasmid (UBOX5-AS1), the 1ncRNA-UBOX5-AS 1 short hairpin RNA (shRNA) (UBOX5-AS1-shRNA), and the corresponding negative scrambled control were obtained from GeneChem (China). The HIF-1 $\alpha$ overexpression plasmid $(H I F-1 \alpha)$, the $H I F-1 \alpha$ small interfering RNA (HIF$1 \alpha$-siRNA), and the corresponding negative scrambled siRNA were obtained from Gemma Pharmaceutical Technology (China). UBOX5-AS1-shRNA and HIF-1 $\alpha$ siRNA were transfected with Neofect ${ }^{\mathrm{TM}}$ DNA transfection reagent (Neofect Biotechnologies, China) at a final concentration of $100 \mathrm{nM}$, and all overexpression plasmids were transfected at $2.0 \mu \mathrm{g}$ in 6 -well plates according to the manufacturer's instructions. All siRNA and shRNA sequences are shown in Table S2.

\section{Cell migration and invasion assays}

Cell migration and invasion potential were evaluated in 24-well Transwell plates (Costar). Briefly, the upper chamber of each insert was coated with $40 \mu \mathrm{L}$ of Matrigel (1:3 diluted with serum-free DMEM/F12 or RPMI 1640 medium) and cultured at $37^{\circ} \mathrm{C}$ for 4 hours. Primary 



Figure 1 The expression of lncRNA-UBOX5-AS1, HIF-1 $\alpha$, E-cadherin, and vimentin in the ectopic endometrium of endometriosis. (A) Real-time polymerase chain reaction (RT-PCR) showed that expression of lncRNA-UBOX5-AS1 was increased in ectopic endometrium tissues of endometriosis. (B,C) Representative western blotting analysis showing HIF-1 $\alpha$, E-cadherin, and vimentin protein expression in the different types of endometrium. $\beta$-actin was used as an internal loading control. ${ }^{*} \mathrm{P}<0.05 ;{ }^{* *} \mathrm{P}<0.01$. lncRNA-UBOX5-AS1, long noncoding RNA UBOX antisense RNA $1 ; H I F-1 \alpha$, hypoxia-inducible factor- $1 \alpha$.

endometrial epithelial cells were seeded in serum-free DMEM/F12 culture medium in the upper chamber, and $500 \mu \mathrm{L}$ of DMEM/F12 culture medium supplemented with $20 \%$ FBS was placed in the lower chamber. Ishikawa cells $\left(5 \times 10^{4} / \mathrm{mL}\right)$ were resuspended in $200 \mu \mathrm{L}$ of culture medium with no serum and plated in the upper chamber. The lower chamber contained $500 \mu \mathrm{L}$ of RPMI 1640 medium supplemented with $10 \% \mathrm{FBS}$. After cultivation for 24 hours, cells in the upper chamber were cleared with wet cotton swabs and inserts were fixed and stained with $0.1 \%$ crystal violet prior to microscopic visualization.

\section{Statistical analysis}

All experimental data were analyzed using Prism ${ }^{\circledR} 8.0$ statistical analysis software (GraphPad, USA) and are presented as mean \pm standard deviation $(\mathrm{SD})$ from at least 3 independent experiments. Unpaired $t$-tests were used to compare the mean of 2 independent groups. One-way analysis of variance (ANOVA) was used to compare means of 2 or more samples. A $\mathrm{P}$ value $<0.05$ was considered statistically significant.

\section{Results}

The expression of HIF-1 $\alpha$, IncRNA-UBOX5-AS1, E-cadberin, and vimentin in ovarian endometriosis

The expression patterns of HIF-1 $\alpha$, lncRNA-UBOX5-AS1, and the EMT-related markers, E-cadherin and vimentin, were examined in ovarian endometriosis tissue samples by qRT-PCR. The expression of lncRNA-UBOX5-AS1 was higher in ectopic endometrial tissue compared to that in eutopic endometrial tissue and normal tissue (Figure 1A). Furthermore, western blotting analysis revealed increased protein expression of $H I F-1 \alpha$ and vimentin in ovarian endometriosis samples, while the expression of E-cadherin was dramatically decreased in the ectopic endometrium of endometriosis (Figure 1B,C). Collectively, the findings suggested that aberrant activation of the HIF-1 $\alpha$ pathway and IncRNA-UBOX5-AS1 may play an important role in the EMT process of endometriosis.

\section{Hypoxia triggered EMT in buman endometrial epitbelial cells}

To explore whether a hypoxic microenvironment induces the EMT process in endometrial cells, the protein expression levels of $H I F-1 \alpha$ and the EMT-related genes, E-cadherin and vimentin, were detected by western blotting assay. As shown in Figure $2 A, B$, after incubating the human endometrial epithelial cells under hypoxic conditions at various time points, the epithelial biomarker E-cadherin was downregulated, while both HIF-1 $\alpha$ and the mesenchymal biomarker vimentin were elevated. Furthermore, after exposure to hypoxia for 24 hours, the morphology of the primary human endometrial epithelial cells became significantly stretched and elongated (Figure 2C). Immunocytochemistry demonstrated 


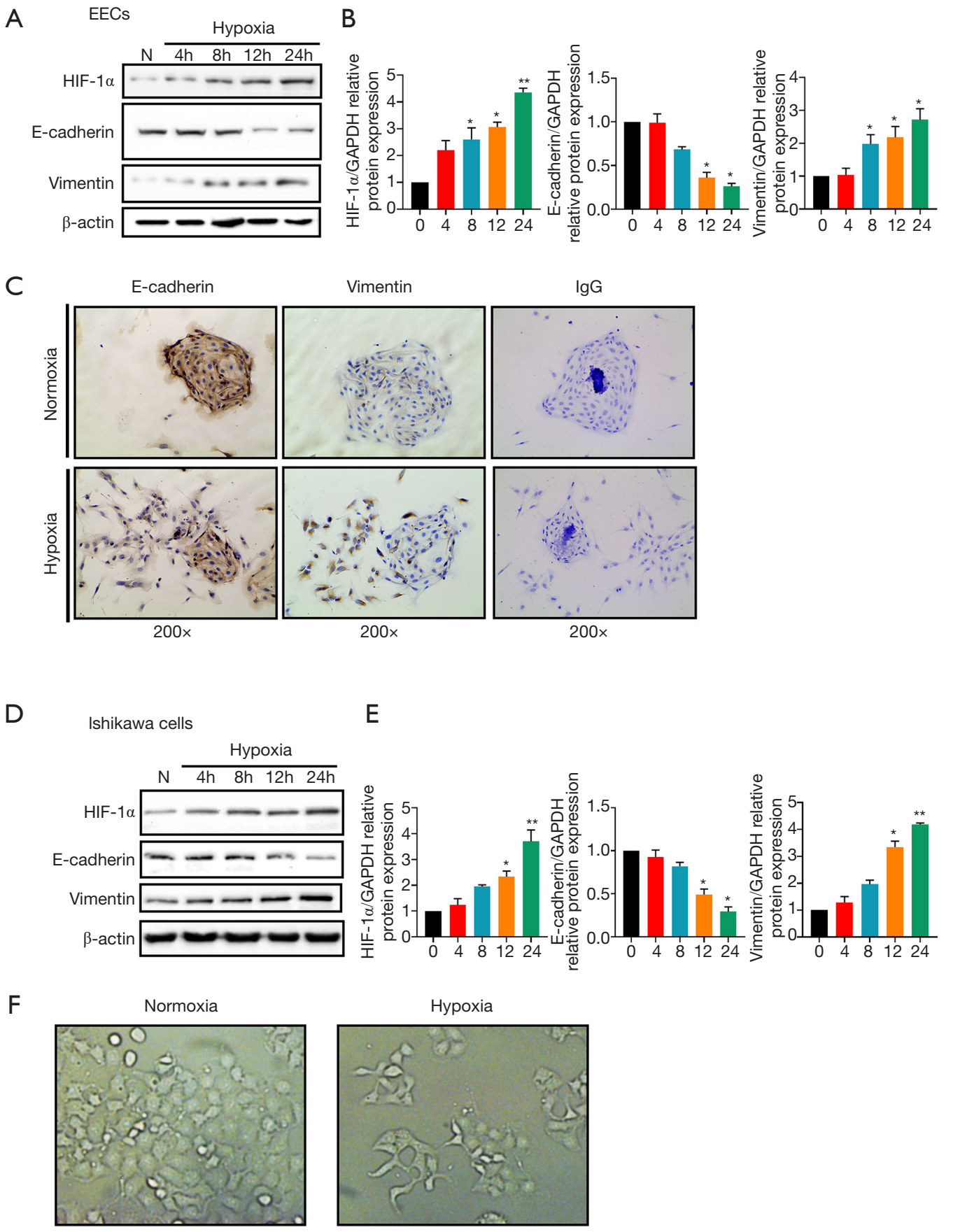

Figure 2 Hypoxia induced epithelial-to-mesenchymal transition (EMT) in human endometrial epithelial cells. (A,B) Representative western blots showing HIF-1 $\alpha$, E-cadherin, and vimentin protein expression in human endometrial epithelial cells cultured under hypoxic conditions for $0,4,8,12$, and 24 hours. (C) Immunocytochemistry analysis of E-cadherin and vimentin in human endometrial epithelial cells cultured under hypoxia for 24 hours (scale bar: 200× magnification). (D,E) Representative western blots showing HIF-1 $\alpha$, E-cadherin, and vimentin protein expression in Ishikawa cells cultured under hypoxic conditions for 0, 4, 8, 12, and 24 hours. (F) Changes in cellular morphology in Ishikawa cells cultured under hypoxic conditions (scale bar: $400 \times$ magnification). $\beta$-actin was used as an internal loading control. ${ }^{*} \mathrm{P}<0.05$; ${ }^{* *} \mathrm{P}<0.01$. HIF-1 $\alpha$, hypoxia-inducible factor- $1 \alpha$. 
A

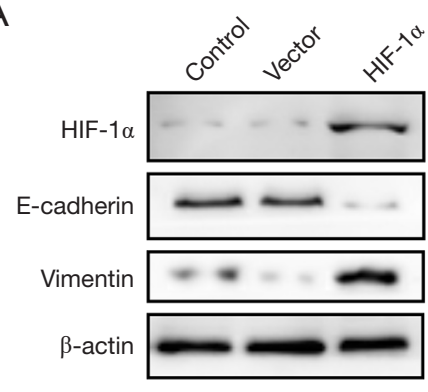

C

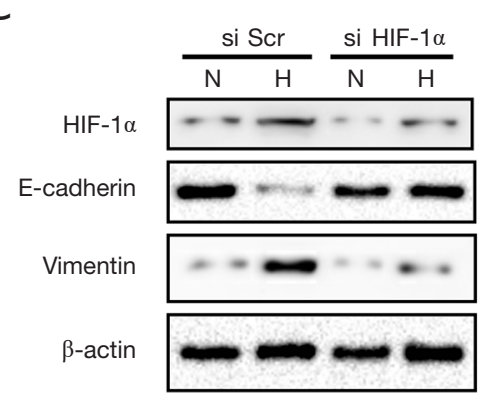

B

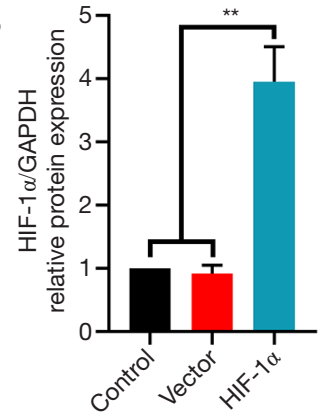

D

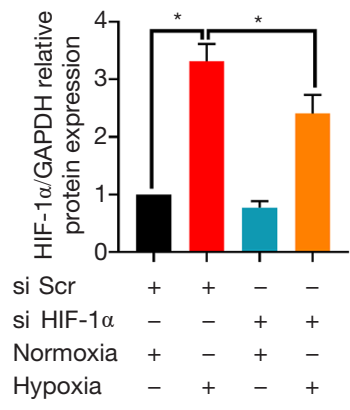

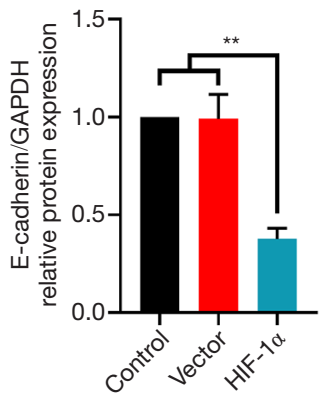
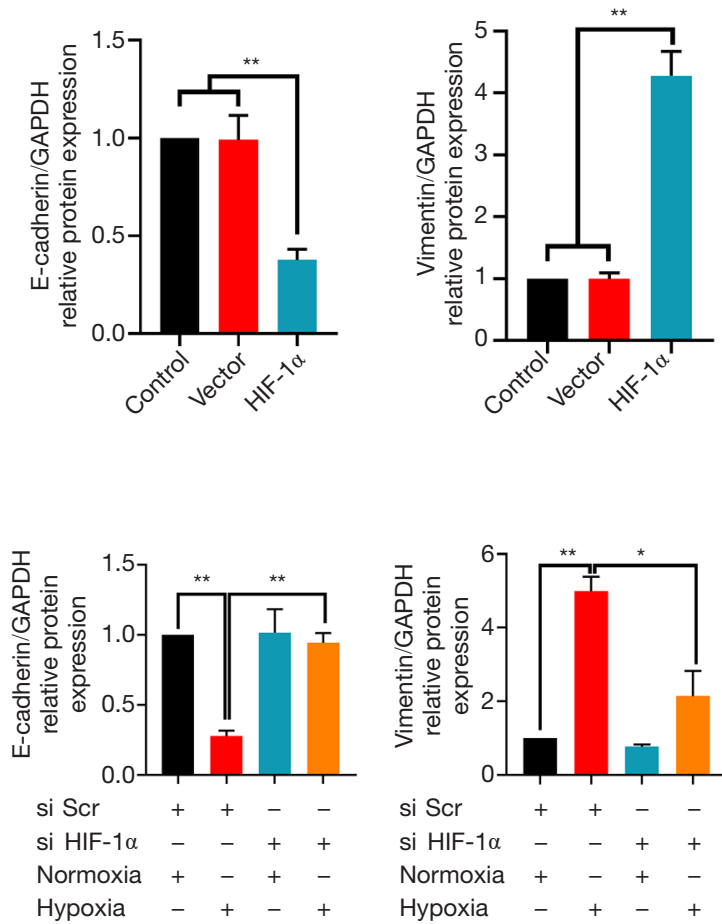

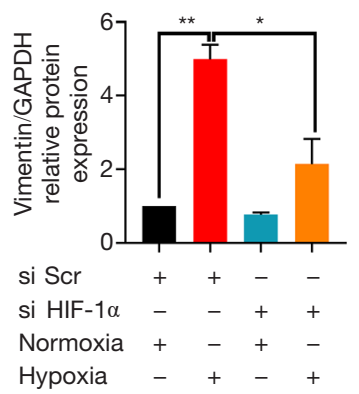

Figure 3 HIF-1 $\alpha$ signaling mediated hypoxia-induced epithelial-to-mesenchymal transition (EMT) in endometrial cells. (A,B) Representative western blots showing HIF-1 $\alpha$, E-cadherin, and vimentin protein expression in Ishikawa cell transfected with vector plasmid or HIF-1 $\alpha$ expression plasmid under normoxic conditions. $\beta$-actin was used as the loading control. (C,D) Representative western blots showing HIF-1 $\alpha$, E-cadherin, and vimentin protein expression in Ishikawa cells transfected with scrambled siRNA or HIF-1 $\alpha$ siRNA under normoxic and hypoxic conditions. $\beta$-actin was used as the loading control. ${ }^{*} \mathrm{P}<0.05 ;{ }^{* *} \mathrm{P}<0.01$. HIF-1 $\alpha$, hypoxia-inducible factor- $1 \alpha$.

weaker E-cadherin membrane localization and stronger intracytoplasmic localization of vimentin in hypoxia-treated human endometrial epithelial cells compared to cells under normoxic conditions (Figure 2C).

The Ishikawa endometrial cancer cell lines were cultured under hypoxic conditions to examine the effects of hypoxia on EMT. As shown in Figure 2D,E, hypoxia resulted in activation of both $H I F-1 \alpha$ signaling and the EMT process. Moreover, hypoxia-treated Ishikawa cells lost their epithelial morphology and assumed a fibroblastlike appearance (Figure $2 F$ ). Collectively, these results are typical of events that occur during the EMT of endometrial epithelial cells.

\section{HIF-1a signaling mediated hypoxia-induced EMT in endometrial cells}

Ishikawa cells were transfected with a HIF-1 $\alpha$ expression plasmid under normoxic conditions and western blotting analyses were conducted. Overexpression of $H I F-1 \alpha$ resulted in elevated expression levels of HIF-1 $\alpha$ and vimentin, as well as decreased expression of E-cadherin (Figure $3 A, B$ ).

Furthermore, HIF-1 $\alpha$ was silenced with specific siRNA. A scrambled siRNA was used as a negative control. After knockdown of HIF-1 $\alpha$ in Ishikawa cells, the promoting effect of hypoxia on EMT was dramatically attenuated (Figure 3C,D). These results indicated that the HIF-1a signaling pathway plays a key role in the hypoxia-triggered EMT process.

\section{Hypoxia promoted migration and invasion in endometrial epithelial cells in a HIF-1 $\alpha$-dependent manner}

The role of the HIF-1 $\alpha$ signaling pathway on cell migration and invasion was examined in Ishikawa cells and primary human endometrial epithelial cells using Transwell assays. Cells exposed to hypoxia demonstrated significantly increased migration and invasion abilities compared to cells cultured under normoxic conditions (Figure 4A,B,C,D). However, after transfection with HIF$1 \alpha$ siRNA, the hypoxia-induced cell migration and invasion 
A

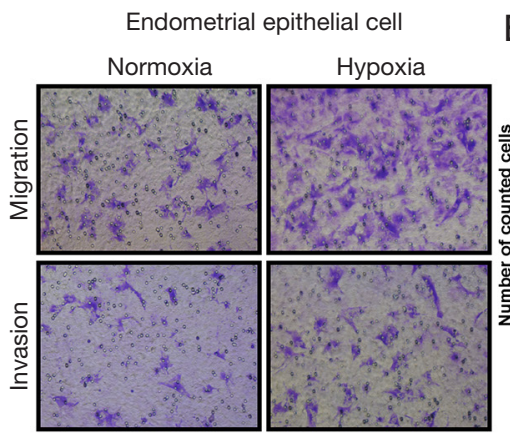

B

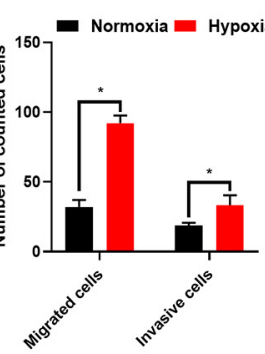

C

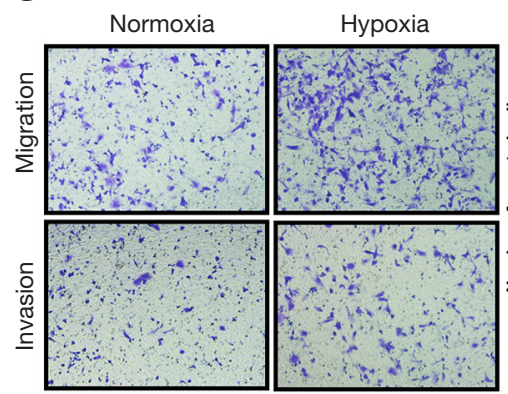

D

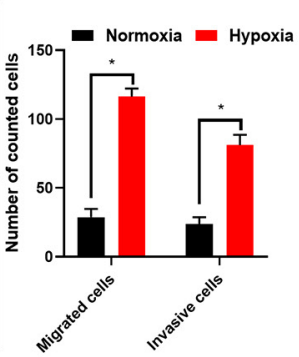

E

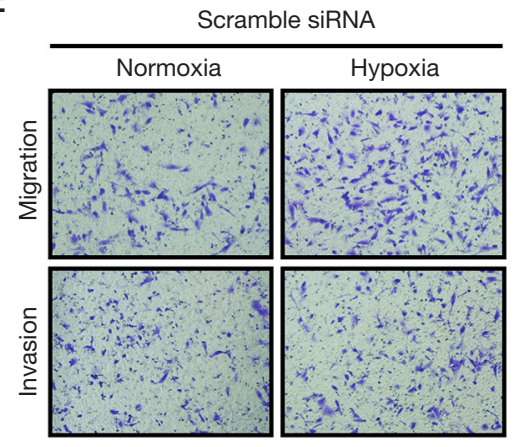



$\mathrm{F}$

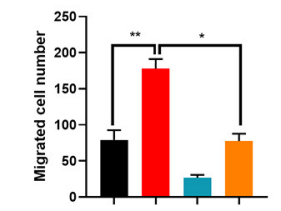

si Scr

si HIF-1 $\alpha--++$

Noxia +-+- Normoxia +-+-

Figure 4 Hypoxia promoted migration and invasion of endometrial epithelial cells in a $H I F-1 \alpha$-dependent manner. (A) Representative photographs of the migration and invasion of endometrial epithelial cells cultured under normoxic and hypoxic conditions. (C) Representative photographs of the migration and invasion of Ishikawa cells cultured under normoxic and hypoxic conditions. (E) Representative photographs of the migration and invasion of Ishikawa cells transfected with scrambled shRNA and $H I F-1 \alpha$ shRNA under normoxic and hypoxic conditions. (B, D, and F) Quantification of the Transwell assay. ${ }^{*} \mathrm{P}<0.05$; ${ }^{* *} \mathrm{P}<0.01$. Photographs were taken at $200 \times$ magnifications. $H I F-1 \alpha$, hypoxia-inducible factor- $1 \alpha$.

ability dramatically decreased (Figure $4 E, F$ ). These results confirmed that hypoxia can promote the migration and invasion of endometrial epithelial cells, with this effect being mediated through $H I F-1 \alpha$ signaling.

\section{Hypoxia upregulated lncRNA-UBOX5-AS1 expression through HIF-1a signaling}

To explore the mechanisms underlying the abnormal elevation of lncRNA-UBOX5-AS1 in human ovarian endometriosis, both primary human endometrial epithelial cells and Ishikawa cells were cultured under hypoxic conditions. RT-PCR analysis revealed a timedependent upregulation of IncRNA-UBOX5-AS1 after hypoxia treatment in both cell types (Figure $5 A, B$ ). As $H I F-1 \alpha$ is the central regulator of hypoxia adaptations, it was speculated that $\operatorname{lncRNA-UBOX5-AS1}$ was transcriptionally regulated by $H I F-1 \alpha$. Therefore, a $H I F-$ $1 \alpha$ expression plasmid was transfected into Ishikawa cells, and RT-PCR results demonstrated that overexpression of $H I F-1 \alpha$ resulted in elevated expression of lncRNAUBOX5-AS1 (Figure 5C). Conversely, when HIF-1 $\alpha$ was silenced in Ishikawa cells using the HIF-1 $\alpha$ siRNA and cells were cultured under hypoxia, the levels of lncRNAUBOX5-AS1 expression were decreased compared to Ishikawa cells transfected with scrambled siRNA (Figure 5D). The above data demonstrated that lncRNAUBOX5-AS1 was upregulated by HIF-1 $\alpha$ under hypoxic conditions.

\section{IncRNA-UBOX5-AS1 contributed to the hypoxia-induced EMT in buman endometrial epithelial cells}

To explore the role of IncRNA-UBOX5-AS1 in hypoxia- 

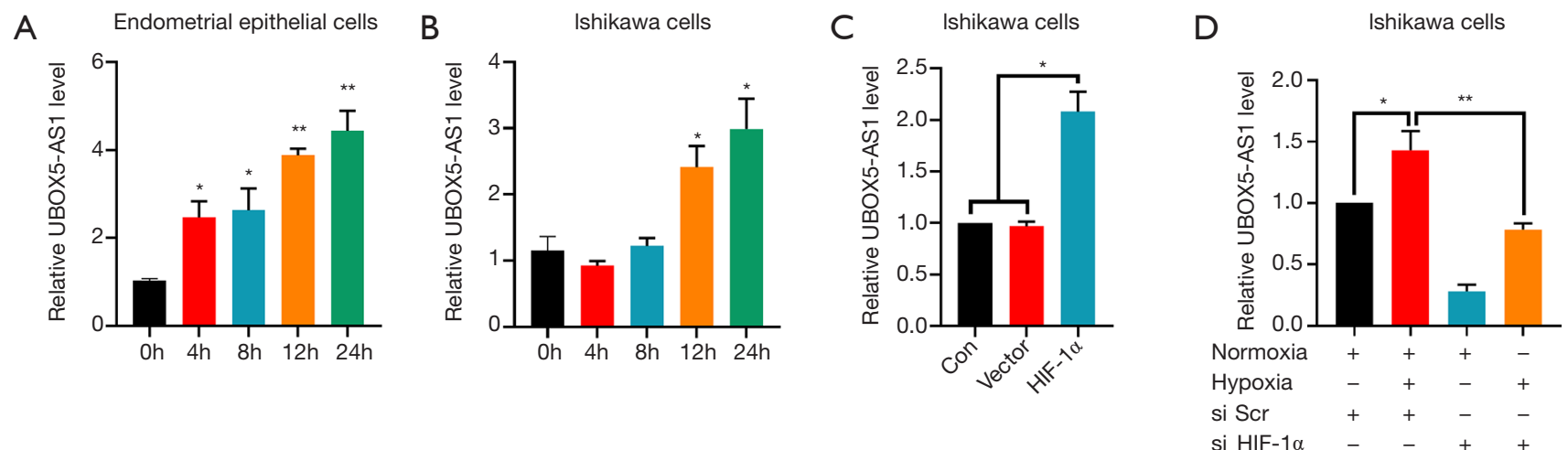

Figure 5 Hypoxia upregulated lncRNA-UBOX5-AS1 expression through HIF-1 $\alpha$ signaling. (A) Human endometrial epithelial cells were treated under hypoxic conditions for various time periods and lncRNA-UBOX5-AS1 levels were detected by quantitative real time polymerase chain reaction (qRT-PCR). (B) Ishikawa cells were incubated under hypoxic conditions for the indicated time periods and lncRNA-UBOX5-AS1 levels were monitored by qRT-PCR. (C) Ishikawa cells were transfected with empty vector or HIF-1 $\alpha$ overexpression plasmid under normoxic conditions and lncRNA-UBOX5-AS1 levels were examined by qRT-PCR. (D) Ishikawa cells were transfected with scrambled siRNA or HIF-1 $\alpha$ target siRNA and treated under hypoxic conditions for 24 hours and the expression of lncRNA-UBOX5-AS1 was assessed by qRT-PCR. ${ }^{*} \mathrm{P}<0.05 ;{ }^{* *} \mathrm{P}<0.01$. lncRNA-UBOX5-AS1, long noncoding RNA UBOX antisense RNA $1 ; H I F-1 \alpha$, hypoxiainducible factor- $1 \alpha$.

induced EMT induction, the lncRNA-UBOX5-AS1 expression plasmid was transfected into Ishikawa cells. Overexpression of lncRNA-UBOX5-AS1 resulted in significantly increased protein expression of vimentin, accompanied with decreased protein expression of E-cadherin compared to control cells and cells transfected with a vector control (Figure $6 A, B$ ). To confirm these results, lncRNA-UBOX5-AS1 shRNA was transfected into Ishikawa cells. Compared to the scrambled shRNA group, cells transfected with the IncRNA-UBOX5-AS1 shRNA showed decreased expression of vimentin and increased expression of E-cadherin under hypoxic conditions (Figure 6C,D). Collectively, these results suggested that IncRNA-UBOX5-AS1 plays a key role in the hypoxiainduced EMT.

\section{Inbibition of IncRNA-UBOX5-AS1 attenuated bypoxia-induced endometrial cell migration and invasion}

To investigate the effect of lncRNA-UBOX5-AS on cell migration and invasion, Transwell assays were performed. Ishikawa cells were transfected with or without lncRNAUBOX5-AS1 shRNA under hypoxic conditions. As shown in Figure $7 A, B$, compared with the normoxia group, cells in the hypoxia group showed increased migration and invasion abilities. However, silencing of lncRNA-UBOX5-
AS1 dramatically attenuated the migration and invasion of Ishikawa cells.

\section{Discussion}

To the best of our knowledge, this is the first study to shed light on the interplay between the peritoneal hypoxic microenvironment and lncRNA UBOX5-AS1 activation and its consequences on the process of EMT and invasion in endometrial epithelial cells. Our data showed that the expression of both IncRNA UBOX5-AS1 and HIF$1 \alpha$ were significantly increased in ovarian endometriotic tissue, and this was positively correlated with the EMT process. Moreover, hypoxia was able to upregulate lncRNAUBOX5-AS1 expression in a HIF-1 $\alpha$-dependent manner. Upregulation of the HIF-1 $\alpha /$ lncRNA-UBOX5-AS1 axis by hypoxia caused an activation of the EMT process, which resulted in enhanced cell invasion potential in endometriosis.

Endometriosis is an enigmatic gynecological disorder in women of childbearing age (1). Currently, the precise etiology and pathogenesis of endometriosis is still poorly understood. The most widely accepted theory involving retrograde menstruation implantation was proposed by Sampson in the 1920s (29). While retrograde menstruation occurs in almost all menstruating females (up to $90 \%$ ), only 
A

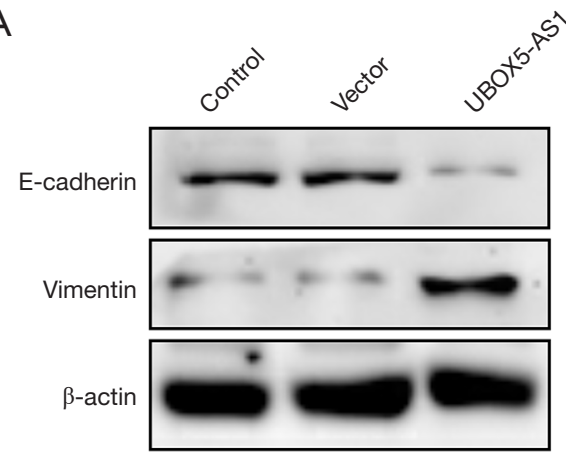

C

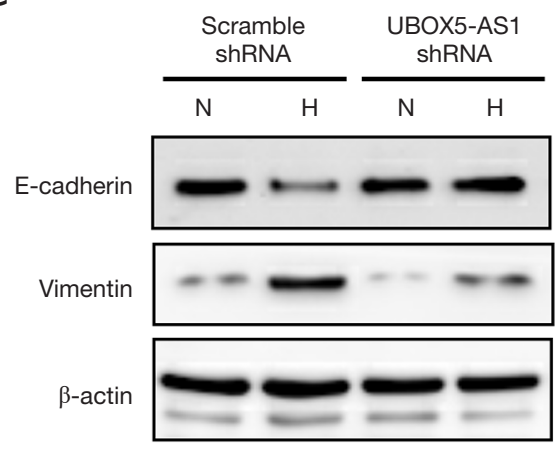

B
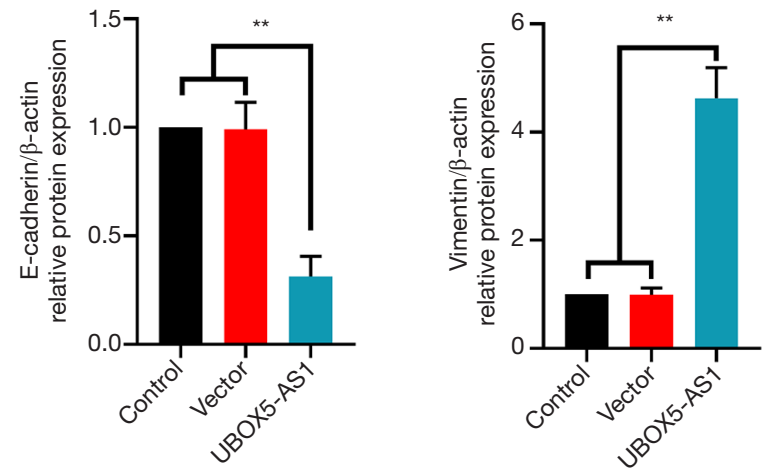

D

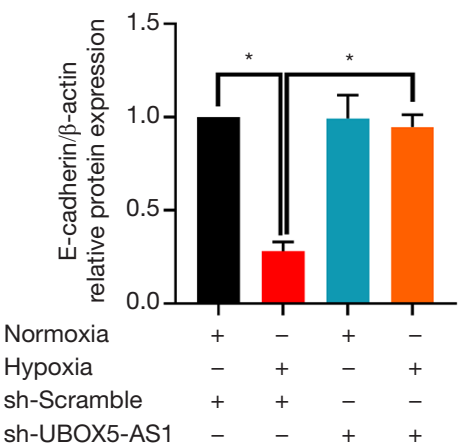

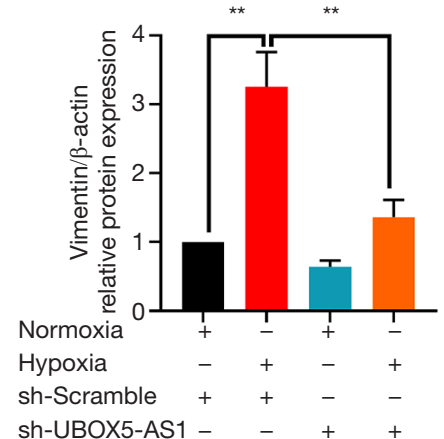

Figure 6 Knockdown of lncRNA-UBOX5-AS1 interfered with hypoxia-induced epithelia-mesenchymal transition (EMT) in human endometrial epithelial cells. $(\mathrm{A}, \mathrm{B})$ Representative western blots showing E-cadherin and vimentin protein levels in Ishikawa cells transfected with empty vector or the UBOX5-AS1 overexpression plasmid under normoxic conditions. (C,D) Representative western blots showing E-cadherin and vimentin protein levels in Ishikawa cells transfected with scrambled shRNA or UBOX5-AS1 shRNA under normoxic or hypoxic conditions. $\beta$-actin was used as an internal loading control. ${ }^{*} \mathrm{P}<0.05 ;{ }^{* *} \mathrm{P}<0.01$. lncRNA-UBOX5-AS1, long noncoding RNA UBOX antisense RNA 1.

about $10 \%$ of women may finally develop endometriosis. Therefore, the development of endometriotic lesions may include other critical factors, such as increased exposure to menstrual debris, abnormal eutopic endometrium, or an altered peritoneal microenvironment.

According to Sampson's theory, shed endometrial fragments lack blood supply and may face hypoxic stress in the peritoneal environment (30). Hypoxia is a central regulator that modulates multiple pathophysiological processes, a majority of which are thought to operate via transcriptional regulation by HIFs (31). HIFs consist of $\alpha$ subunits and $\beta$ subunits to form the heterodimeric complex. HIF- $1 \beta$ is constitutively expressed under both normoxic and hypoxic conditions. In contrast, the HIF-1 $\alpha$ subunit is primarily modulated by cellular oxygen concentrations. Normally, HIF-1 $\alpha$ is bound to the von Hippel-Lindau protein (VHL) and is rapidly degraded by the ubiquitinproteasome system when cells are under normoxic conditions. However, under a hypoxic microenvironment, hydroxylation of $H I F-1 \alpha$ is inhibited, allowing $H I F-$ $1 \alpha$ to avoid degradation and increasing its stability (32). Accumulating evidence suggests that peritoneal local hypoxia plays a critical role in the development of ovarian endometriosis, involving angiogenesis, inflammation, adhesion, invasion, and survival (33-39) (see Figure S2). Additionally, our previous research demonstrated that the expression of $H I F-1 \alpha$ was markedly increased in ovarian endometrial tissues $(5,7)$.

Accumulating reports have revealed a crucial role for hypoxia in the invasion/migration of endometriosis (40). EMT, in which primary epithelial cells transform into loosely organized mesenchymal-like cells with increased 
A
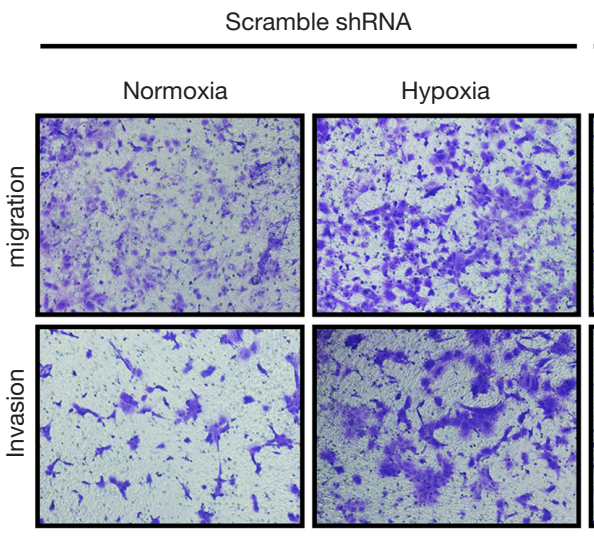

B

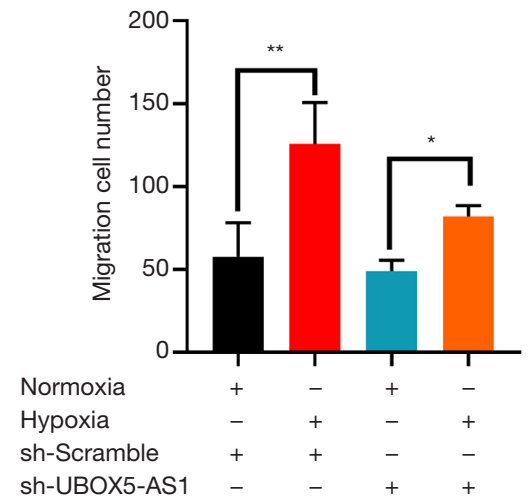

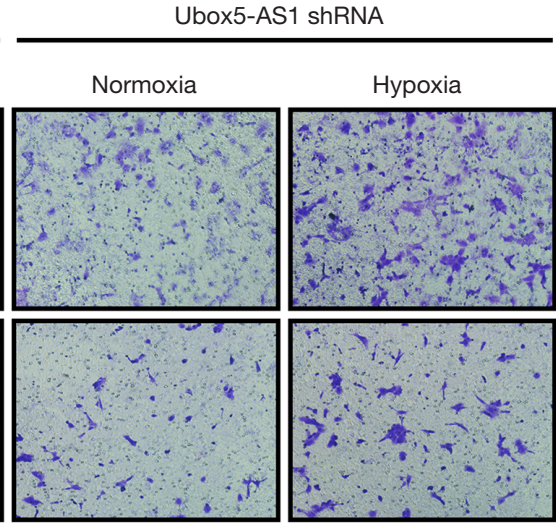

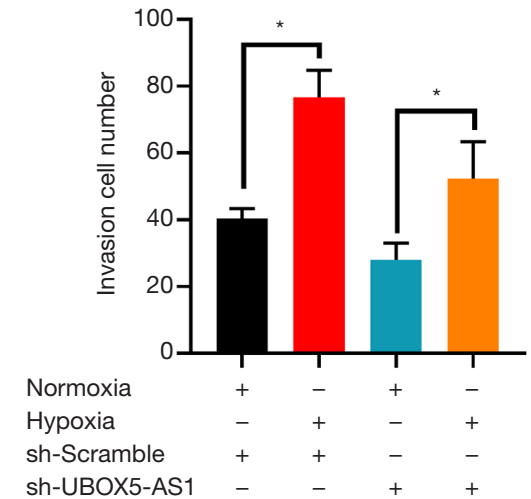

Figure 7 Inhibition of lncRNA-UBOX5-AS1 attenuated hypoxia-induced endometrial cell migration and invasion. (A) Ishikawa cells were transfected with UBOX5-AS1 shRNA or scrambled shRNA, and incubated under normoxic or hypoxic conditions. Cell migration and invasion potential were evaluated by Transwell assays. (B) Quantification of the Transwell assays. ${ }^{*} \mathrm{P}<0.05$; ${ }^{* *} \mathrm{P}<0.01$. Photographs were taken at 200× magnifications. lncRNA-UBOX5-AS1, long noncoding RNA UBOX antisense RNA 1.

cell motility and invasion, has been demonstrated to be a critical step in the initial formation of endometriosis (17). Both hypoxia and overexpression of $H I F-1 \alpha$ have been shown to trigger EMT and invasive phenotypes (41), possibly via $H I F-1 \alpha$-dependent accumulation of EMTrelated key regulators, such as Snail, Twist, ZEB1, and ZEB2. Chen et al. demonstrated that hypoxia can promote EMT and proliferation of pancreatic cancer cells through activation of the TWIST gene (42). Joseph et al. showed that hypoxia enhances the migration and invasion of glioblastoma cells by promoting the $H I F-1 \alpha$-ZEB 1 axis, thereby mediating the EMT process (43). This current study demonstrated that hypoxia could trigger the EMT process in both primary endometrial epithelial cells and Ishikawa cells. Moreover, the data suggested that HIF$1 \alpha$ signaling is required for hypoxia-induced migration, invasion, and EMT. Collectively, the above results demonstrated that hypoxia can promote endometrial cell migration, invasion, and EMT via the HIF- $1 \alpha$ signaling pathway.

Recently, an increasing number of reports have shown that lncRNAs are vital for the regulation of multiple biological processes, including proliferation, invasion, and EMT. Dysregulation of lncRNAs may also contribute to the pathological processes of endometriosis. Ghazal et al. reported that the elevation of lncRNA-H19 expression promoted proliferation of endometriotic stromal cell via the downregulation of let-7 to target insulin-like growth factor 1 receptor (IGF1R) (44). Zhang et al. demonstrated that knockdown of lncRNA-CCDC144NL-AS1 attenuated endometrial stromal cells migration and invasion (45). LncRNA UBOX5-AS1 is a recently identified lncRNA that is highly expressed in the ectopic endometrium of ovarian endometriosis. However, little is known about 
its function in endometriosis (26). Furthermore, prior research has suggested that the hypoxic microenvironment is a vital driving force affecting the expression patterns of lncRNAs. Deng and colleagues demonstrated that hypoxia promotes metastasis and progression of pancreatic cancer via lncRNA-BX111-mediated ZEB1 transcription (46). In another study, Xue et al. found that hypoxic exosomes could upregulate the expression of lncRNA-UCA1, which resulted in aggressive bladder tumor growth and development (47). However, it remains to be determined whether lncRNAUBOX5-AS1 is potentially regulated by hypoxic conditions in ovarian endometriosis. The findings of our study showed that both lncRNA-UBOX5-AS1 and HIF-1 $\alpha$ were elevated in ectopic endometriotic tissue. Furthermore, lncRNAUBOX5-AS1 was upregulated by hypoxia in a timedependent manner and was modulated by $H I F-1 \alpha$ signaling in human endometrial epithelial cells. Taken together, this study demonstrated that hypoxia can elevate the levels of IncRNA-UBOX5-AS1 in a HIF-1 $\alpha$-dependent manner in endometrial cells.

Both IncRNA-UBOX5-AS1 and the EMT process can be upregulated by hypoxic stress. However, the exact relationship between IncRNA-UBOX5-AS1 and the EMT process under hypoxic conditions in the context of endometriosis remains to be fully elucidated. Therefore, it is critical to investigate the regulatory role of lncRNAUBOX5-AS1 on the EMT process under hypoxic conditions in endometriosis. Previous studies have indicated a role for hypoxic-induced regulation of IncRNAs on the EMT process. Zhang and colleagues reported that the IncRNA, HOTTIP, promotes the hypoxia-induced EMT process by modulating the microRNA (miR)-101/ ZEB1 axis in malignant glioma (48). In pancreatic cancer, hypoxia was found to promote tumor metastasis through the IncRNA NORAD-induced EMT process (49). These reports lead us to speculate that lncRNA-UBOX5-AS1 may also function by regulating the EMT of endometriosis in the hypoxic microenvironment. Herein, we demonstrated that knockdown of lncRNA-UBOX5-AS1 could reverse the hypoxia-triggered EMT process in human endometrial epithelial cells. The results also showed that downregulation of lncRNA-UBOX5-AS1 attenuated cell migration and invasion under hypoxic conditions. This present study is the first to demonstrate the role of lncRNA-UBOX5-AS1 in the regulation of the hypoxia-induced EMT process in ovarian endometriosis.

This investigation has a number of important limitations that should be acknowledged. First, the current study only examined the proliferative phase of the normal, eutopic, and ectopic endometrium of ovarian endometriosis, with only a relatively small sample size, which may constrain the generalizability of our results. Future studies with larger sample sizes are needed to further validate these findings. Second, since primary endometrial epithelial cells are very difficult to grow and passage for transfection and Transwell experiments, the human endometrial carcinoma Ishikawa cell line was used. Ishikawa cells are a well-differentiated human endometrial adenocarcinoma cell line that expresses estrogen, progesterone, and androgen receptors, and many investigations have used this cell line to study human endometriosis. Third, the exact mechanisms of lncRNAUBOX5-AS1-mediated promotion of the EMT process in human endometrial epithelial cells remained unclear. Our previous study demonstrated that estradiol promotes EMT in endometriosis via MALAT1/miR200s sponge function (50). However, the regulatory mechanisms of lncRNA-UBOX5AS1 on EMT under hypoxic conditions are still poorly understood. Last, the expression of lncRNA-UBOX5-AS1 and its functions in endometriosis should be validated in future in vivo experiments. Since the regulatory mechanisms for EMT are complex, the precise mechanisms by which lncRNA-UBOX5-AS1 regulate EMT warrant further investigation.

In summary, this current research is the first to shed light on the role of IncRNA-UBOX5-AS1 in hypoxiainduced EMT. Hypoxia can both increase lncRNAUBOX5-AS1 expression in a $H I F-1 \alpha$-dependent manner and stimulate EMT in endometrial epithelial cells. Furthermore, enhanced lncRNA-UBOX5-AS1 expression promoted EMT and metastasis under hypoxic conditions. Inhibition of lncRNA-UBOX5-AS1 significantly attenuated the malignant phenomena induced by hypoxia (Figure 8). Recent studies demonstrated that dysregulated lncRNAs are potential diagnostic biomarkers and therapeutic targets. As lncRNA-UBOX5-AS1 may be involved in the pathogenesis of ovarian endometriosis, further studies should focus on elucidating the specific molecular mechanisms of lncRNAUBOX5-AS1 to provide novel insights into the diagnosis and treatment of ovarian endometriosis.

\section{Acknowledgments}

The authors would like to thank Peng Zhang for his critical review of the manuscript. 


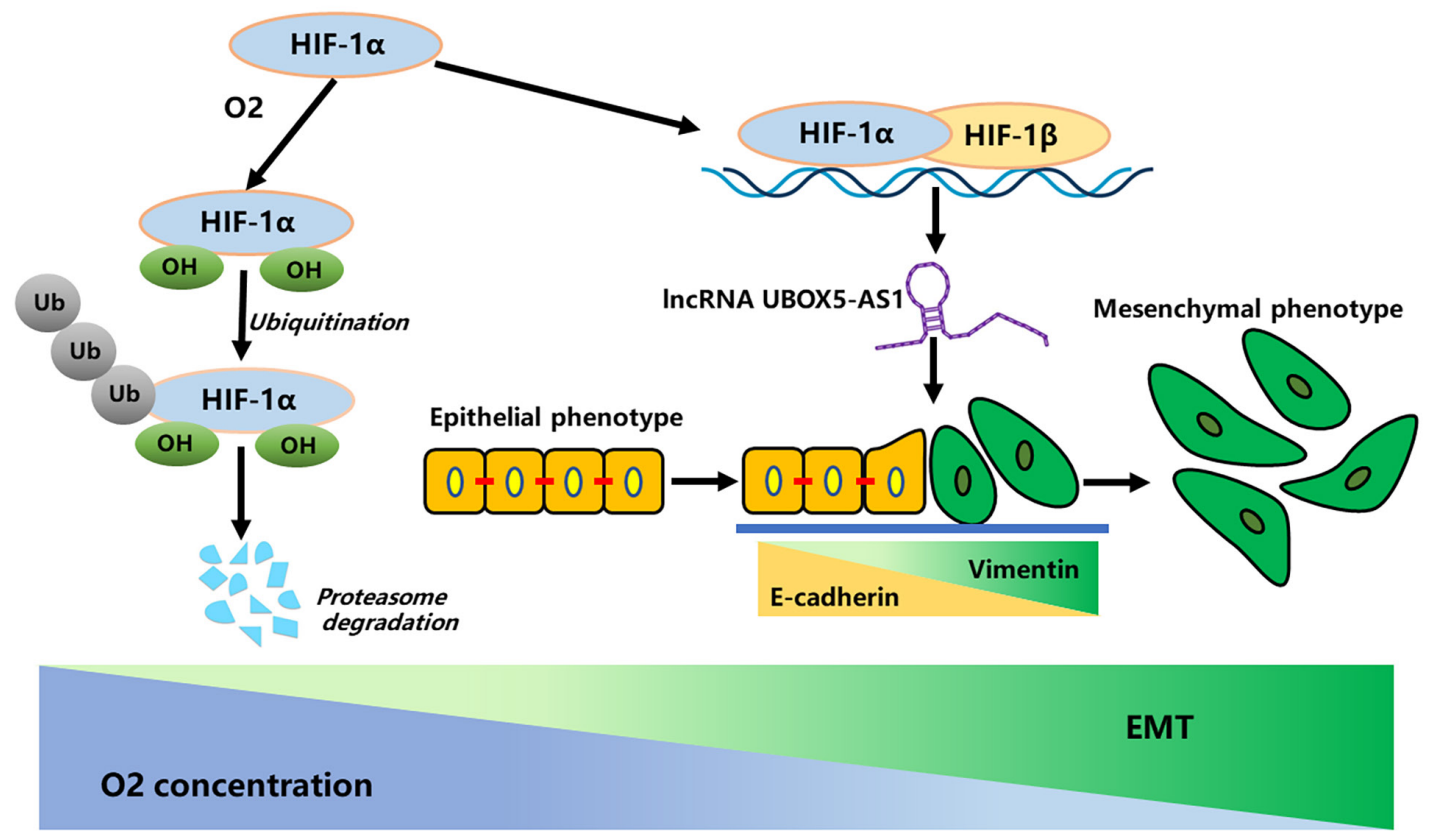

Figure 8 The schematic model of the role and underlying mechanisms of lncRNA-UBOX5-AS1 during hypoxia/HIF-1 $\alpha$-induced epithelialto-mesenchymal transition (EMT) in human endometrial epithelial cells. Under a hypoxic peritoneal microenvironment, the HIF-1 $\alpha$ protein is stabilized and combined with HIF-1 $\beta$ to form a heterodimeric protein complex. This complex is then translocated into the nucleus and regulates the transcription of downstream targets of lncRNA-UBOX5-AS1 which contribute to the EMT process in human endometrial epithelial cells. lncRNA-UBOX5-AS1, long noncoding RNA UBOX antisense RNA 1; HIF-1 $\alpha$, hypoxia-inducible factor-1 $\alpha$.

Funding: This work was supported by grants from the National Natural Science Foundation of China (no. 8197061339 to Yi Liu; no. 81701417 to Wenqian Xiong; no. 82001524 to Hengwei Liu; no. 81901460 to Ling Zhang), the Natural Science Foundation of Hubei Province (mo. 2020 CFB310 to Hengwei Liu), the Fundamental Research Fund for the Central Universities (no. 2042020kf0154 to Hengwei Liu), the Zhongnan Hospital of Wuhan University Science, Technology and Innovation Cultivating Fund (no. znpy2019077 to Hengwei Liu), the Program of Excellent Doctoral (Postdoctoral) of Zhongnan Hospital of Wuhan University (no. ZNYB2019009 to Hengwei Liu), the Medjaden Academy and Research Foundation for Young Scientists (no. MJR20190005 to Hengwei Liu), and the NIH Award (no. NIH HD076257 to Zhibing Zhang).

\section{Footnote}

Reporting Checklist: The authors have completed the MDAR checklist. Available at http://dx.doi.org/10.21037/atm-204546
Data Sharing Statement: Available at http://dx.doi. org/10.21037/atm-20-4546

Conflicts of Interest: All authors have completed the ICMJE uniform disclosure form (available at http://dx.doi. org/10.21037/ atm-20-4546). HL served as an unpaid Section Editor for the Annals of Translational Medicine from January 2020 to December 2020. The other authors have no conflicts of interest to declare.

Ethical Statement: The authors are accountable for all aspects of the work in ensuring that questions related to the accuracy or integrity of any part of the work are appropriately investigated and resolved. The study was conducted in accordance with the Declaration of Helsinki (as revised in 2013). The study was approved by the local Ethics Committee of Tongji Medical College, Huazhong University of Science (no. IORG0003571), and informed consent was obtained from all patients.

Open Access Statement: This is an Open Access article 
distributed in accordance with the Creative Commons Attribution-NonCommercial-NoDerivs 4.0 International License (CC BY-NC-ND 4.0), which permits the noncommercial replication and distribution of the article with the strict proviso that no changes or edits are made and the original work is properly cited (including links to both the formal publication through the relevant DOI and the license). See: https://creativecommons.org/licenses/by-nc-nd/4.0/.

\section{References}

1. Giudice LC. Endometriosis. N Engl J Med 2010;362:2389-98.

2. Vercellini P, Viganò P, Somigliana E, et al. Endometriosis: pathogenesis and treatment. Nat Rev Endocrinol 2014;10:261.

3. Sampson JA. Metastatic or embolic endometriosis, due to the menstrual dissemination of endometrial tissue into the venous circulation. Am J Pathol 1927;3:93.

4. Oral E, Olive DL, Arici A. The peritoneal environment in endometriosis. Hum Reprod Update 1996;2:385-98.

5. Hsiao KY, Lin SC, Wu MH, et al. Pathological functions of hypoxia in endometriosis. Front Biosci (Elite Ed) 2015;7:309-21.

6. Zhan L, Wang W, Zhang Y, et al. Hypoxia-inducible factor-1alpha: A promising therapeutic target in endometriosis. Biochimie 2016;123:130-7.

7. Liu H, Zhang Z, Xiong W, et al. Hypoxia-inducible factor- $1 \alpha$ promotes endometrial stromal cells migration and invasion by upregulating autophagy in endometriosis. Reproduction (Cambridge, England) 2017;153:809.

8. Weidemann A, Johnson R. Biology of HIF-1 $\alpha$. Cell death and differentiation 2008;15:621.

9. Masoud GN, Li W. HIF-1 $\alpha$ pathway: role, regulation and intervention for cancer therapy. Acta Pharmaceutica Sinica B 2015;5:378-89.

10. Yang $M H, W u M Z$, Chiou SH, et al. Direct regulation of TWIST by HIF-1 $\alpha$ promotes metastasis. Nat Cell Biol 2008;10:295.

11. Zhang Q, Dong P, Liu X, et al. Enhancer of Zeste homolog 2 (EZH2) induces epithelial-mesenchymal transition in endometriosis. Sci Rep 2017;7:6804.

12. Zhang Q, Duan J, Liu X, et al. Platelets drive smooth muscle metaplasia and fibrogenesis in endometriosis through epithelial-mesenchymal transition and fibroblastto-myofibroblast transdifferentiation. Mol Cell Endocrinol 2016;428:1-16.

13. Thiery JP, Acloque H, Huang RY, et al. Epithelialmesenchymal transitions in development and disease. Cell 2009;139:871-90.
14. Gonzalez DM, Medici D. Signaling mechanisms of the epithelial-mesenchymal transition. Sci Signal 2014;7:re8.

15. Jing Y, Han Z, Zhang S, et al. Epithelial-Mesenchymal Transition in tumor microenvironment. Cell Biosci 2011;1:29.

16. Marie-Egyptienne DT, Lohse I, Hill RP. Cancer stem cells, the epithelial to mesenchymal transition (EMT) and radioresistance: potential role of hypoxia. Cancer Lett 2013;341:63-72.

17. Matsuzaki S, Darcha C. Epithelial to mesenchymal transition-like and mesenchymal to epithelial transitionlike processes might be involved in the pathogenesis of pelvic endometriosis. Hum Reprod 2012;27:712-21.

18. Zhang J, Zhang Q, Lou Y, et al. Hypoxia-inducible factor- $1 \alpha /$ interleukin- $1 \beta$ signaling enhances hepatoma epithelial-mesenchymal transition through macrophages in a hypoxic-inflammatory microenvironment. Hepatology 2018;67:1872-89.

19. Zhang X, Sai B, Wang F, et al. Hypoxic BMSC-derived exosomal miRNAs promote metastasis of lung cancer cells via STAT3-induced EMT. Mol Cancer 2019;18:40.

20. Quinn JJ, Chang HY. Unique features of long noncoding RNA biogenesis and function. Nat Rev Genetics 2016;17:47.

21. Li X, Wu Z, Fu X, et al. Long noncoding RNAs: insights from biological features and functions to diseases. Med Res Rev 2013;33:517-53.

22. Wang P, Yuan Y. LncRNA-ROR alleviates hypoxiatriggered damages by downregulating miR-145 in rat cardiomyocytes H9c2 cells. J Cell Physiol 2019;234:23695-704.

23. Gugnoni M, Ciarrocchi A. Long Noncoding RNA and Epithelial Mesenchymal Transition in Cancer. Int J Mol Sci 2019;20:1924.

24. Zhao M, Qiu Y, Yang B, et al. long non-coding RNAs involved in gynecological cancer. Int J Gynecol Cancer 2014;24:1140-5.

25. Panir K, Schjenken JE, Robertson SA, et al. Non-coding RNAs in endometriosis: a narrative review. Hum Reprod Update 2018;24:497-515.

26. Wang WT, Sun YM, Huang W, et al. Genome-wide Long Non-coding RNA Analysis Identified Circulating LncRNAs as Novel Non-invasive Diagnostic Biomarkers for Gynecological Disease. Sci Rep 2016;6:23343.

27. Johnson NP, Hummelshoj L, Adamson GD, et al. World Endometriosis Society consensus on the classification of endometriosis. Hum Reprod 2017;32:315-24.

28. Kaczynski P, Kowalewski MP, Waclawik A. Prostaglandin 
F2alpha promotes angiogenesis and embryo-maternal interactions during implantation. Reproduction 2016;151:539-52.

29. Sampson JA. Peritoneal endometriosis due to the menstrual dissemination of endometrial tissue into the peritoneal cavity. Am J Obstetrics Gynecol 1927;14:422-69.

30. Maybin JA, Murray AA, Saunders PT, et al. Hypoxia and hypoxia inducible factor- $1 \alpha$ are required for normal endometrial repair during menstruation. Nat Commun 2018;9:295.

31. Semenza GL, Agani F, Feldser D, et al. Hypoxia, HIF1 , and the pathophysiologi of common human diseases. Oxygen Sensing. Springer, 2002:123-30.

32. Semenza GL. Hypoxia-inducible factors in physiology and medicine. Cell 2012;148:399-408.

33. Liu H, Zhang Z, Xiong W, et al. Long non-coding RNA MALAT1 mediates hypoxia-induced pro-survival autophagy of endometrial stromal cells in endometriosis. J Cell Mol Med 2019;23:439-52.

34. Lin X, Dai Y, Xu W, et al. Hypoxia Promotes Ectopic Adhesion Ability of Endometrial Stromal Cells via TGF- $\beta 1 /$ Smad Signaling in Endometriosis. Endocrinology 2018;159:1630-41.

35. Lin SC, Lee HC, Hou PC, et al. Targeting hypoxiamediated YAP1 nuclear translocation ameliorates pathogenesis of endometriosis without compromising maternal fertility. J Pathol 2017;242:476-87.

36. Hsiao KY, Chang N, Tsai JL, et al. Hypoxia-inhibited DUSP2 expression promotes IL-6/STAT3 signaling in endometriosis. Am J Reprod Immunol 2017;78.

37. Xiong W, Zhang L, Xiong Y, et al. Hypoxia Promotes Invasion of Endometrial Stromal Cells via HypoxiaInducible Factor $1 \alpha$ Upregulation-Mediated $\beta$-Catenin Activation in Endometriosis. Reprod Sci 2016;23:531-41.

38. Fu JL, Hsiao KY, Lee HC, et al. Suppression of COUPTFII upregulates angiogenin and promotes angiogenesis in endometriosis. Hum Reprod 2018;33:1517-27.

39. Xu TX, Zhao SZ, Dong M, et al. Hypoxia responsive miR-210 promotes cell survival and autophagy of endometriotic cells in hypoxia. Eur Rev Med Pharmacol Sci 2016;20:399-406.

40. Donnez O, Orellana R, Van Kerk O, et al. Invasion process of induced deep nodular endometriosis in an experimental baboon model: similarities with collective cell migration? Fertility Sterility 2015;104:491-7.e2.

41. Yang MH, Wu KJ. TWIST activation by hypoxia inducible factor-1 (HIF-1): implications in metastasis and development. Cell Cycle 2008;7:2090-6.
42. Chen S, Chen JZ, Zhang JQ, et al. Hypoxia induces TWIST-activated epithelial-mesenchymal transition and proliferation of pancreatic cancer cells in vitro and in nude mice. Cancer Lett 2016;383:73-84.

43. Joseph JV, Conroy S, Pavlov K, et al. Hypoxia enhances migration and invasion in glioblastoma by promoting a mesenchymal shift mediated by the HIF1alpha-ZEB1 axis. Cancer Lett 2015;359:107-16.

44. Ghazal S, McKinnon B, Zhou J, et al. H19 lncRNA alters stromal cell growth via IGF signaling in the endometrium of women with endometriosis. EMBO Mol Med 2015;7:996-1003.

45. Zhang $\mathrm{C}, \mathrm{Wu} \mathrm{W}$, Zhu H, et al. Knockdown of long noncoding RNA CCDC144NL-AS1 attenuates migration and invasion phenotypes in endometrial stromal cells from endometriosisdagger. Biol Reprod 2019;100:939-49.

46. Deng SJ, Chen HY, Ye Z, et al. Hypoxia-induced LncRNA-BX111 promotes metastasis and progression of pancreatic cancer through regulating ZEB1 transcription. Oncogene 2018;37:5811-28.

47. Xue M, Chen W, Xiang A, et al. Hypoxic exosomes facilitate bladder tumor growth and development through transferring long non-coding RNA-UCA1. Mol Cancer 2017;16:143.

48. Zhang S, Wang W, Liu G, et al. Long non-coding RNA HOTTIP promotes hypoxia-induced epithelialmesenchymal transition of malignant glioma by regulating the miR-101/ZEB1 axis. Biomed Pharmacother 2017;95:711-20.

49. Li H, Wang X, Wen C, et al. Long noncoding RNA NORAD, a novel competing endogenous RNA, enhances the hypoxia-induced epithelial-mesenchymal transition to promote metastasis in pancreatic cancer. Mol Cancer 2017;16:169.

50. Du Y, Zhang Z, Xiong W, et al. Estradiol promotes EMT in endometriosis via MALAT1/miR200s sponge function. Reproduction 2019;157:179-88.

(English Language Editor: J. Teoh; Quality Control Editor: J. Gray)

Cite this article as: Liu $\mathrm{H}$, He H, Zhang Z, Wang L, Zhang L, Liu Y, Xiong W. Upregulation of the long noncoding RNA UBOX5 antisense RNA 1 (UBOX5-AS1) under hypoxic conditions promotes epithelial-mesenchymal transition in endometriosis. Ann Transl Med 2021;9(9):790. doi: 10.21037/ atm-20-4546 


\section{Supplementary}

Table S1 Clinical characteristics of patients

\begin{tabular}{|c|c|c|c|c|}
\hline & \multicolumn{3}{|c|}{ Samples used for Western blot } & $\begin{array}{l}\text { Samples used for primary } \\
\text { endometrial epithelial cell }\end{array}$ \\
\hline & Endometrium & Endometrium & Endometrium & cultures \\
\hline Number of cases & 11 & 10 & 9 & 70 \\
\hline Age & $31.3 \pm 2.1$ & $30.4 \pm 3.2$ & $36.3 \pm 2.5$ & $32.2 \pm 2.7$ \\
\hline \multicolumn{5}{|l|}{ \#rASRM stage } \\
\hline III & & 11 & 16 & \\
\hline IV & & 19 & 16 & \\
\hline
\end{tabular}

Median (range). Revised American Society for Reproductive Medicine classification (rASRM: American Society for Reproductive Medicine, 1997).

A anti-E-cadherin ab

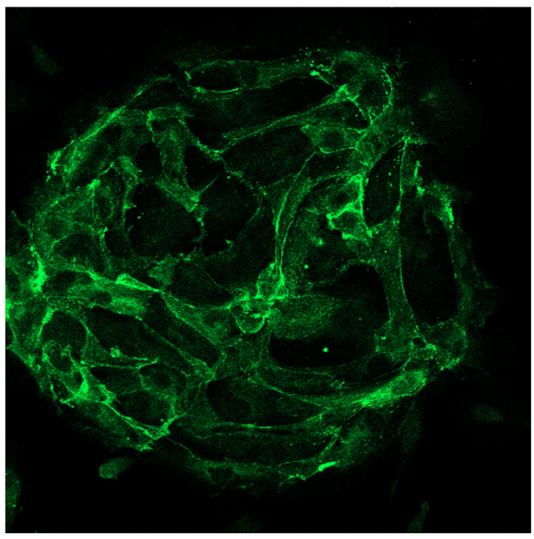

B

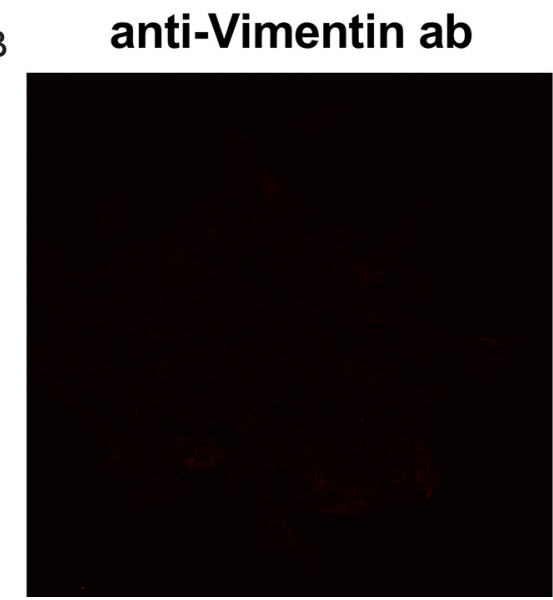

DAPI



DAPI

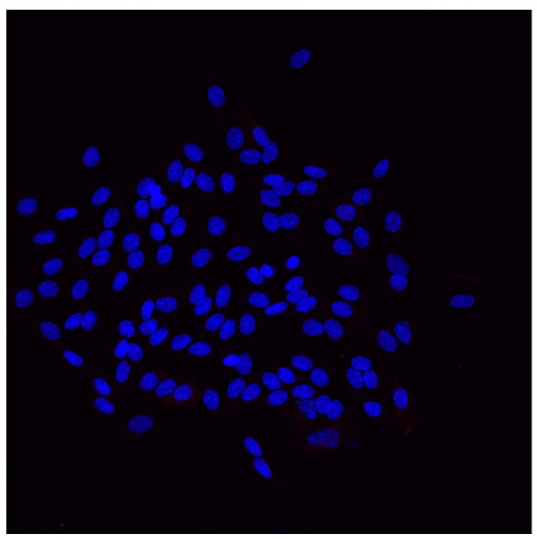

Merge

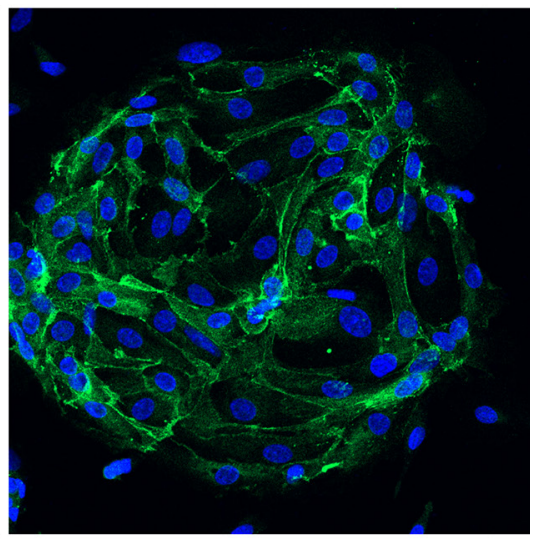

Merge

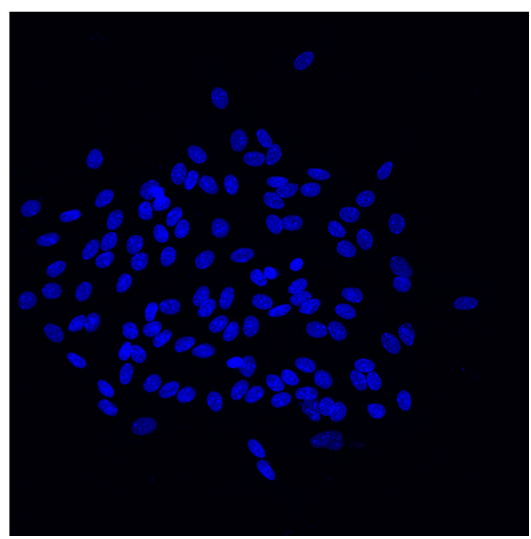

Figure S1 Identification of markers for isolation of human endometrial epithelial cells. Immuofluorescence microscopy staining of (A) E-cadherin in green represents and (B) Vimentin in red represents. Blue signal represents nuclear DNA staining by DAPI. Human endometrial epithelial cells were judged by negative cellular staining for Vimentin and positive staining for E-cadherin. Photographs were taken at magnifications of 1600x. Data presented are from three independent experiments. 
Table S2 Primer sequences used for real-time RT-PCR and siRNA analyses

\begin{tabular}{lll}
\hline Gene & primier & sequence (5'-3') \\
\hline UBOX5-AS1 (for qRT-PCR) & Forward & GAAAACAGGCCAGGGTTAG \\
UBOX5-AS1 shRNA & Reverse & GGACTCGGGAGGGATGAAG \\
& Forward & GGCAAUGUUUUACACUAUUTT \\
scramble shRNA & Reverse & AAUAGUGUAAAACAUUGCCT \\
HIF-1 $\alpha$ siRNA & Forward & GGCAAUGUUUUACACUAUUTT \\
scramble siRNA & Forward & AAUAGUGUAAAACAUUGCCTA \\
& Reverse & GCUGGAGACAAUCAUAUTTA \\
& Forward & AACUUCACAAUCGUAACUGGU \\
\hline
\end{tabular}

Table S3 Commercial sources and characteristics of antibodies used

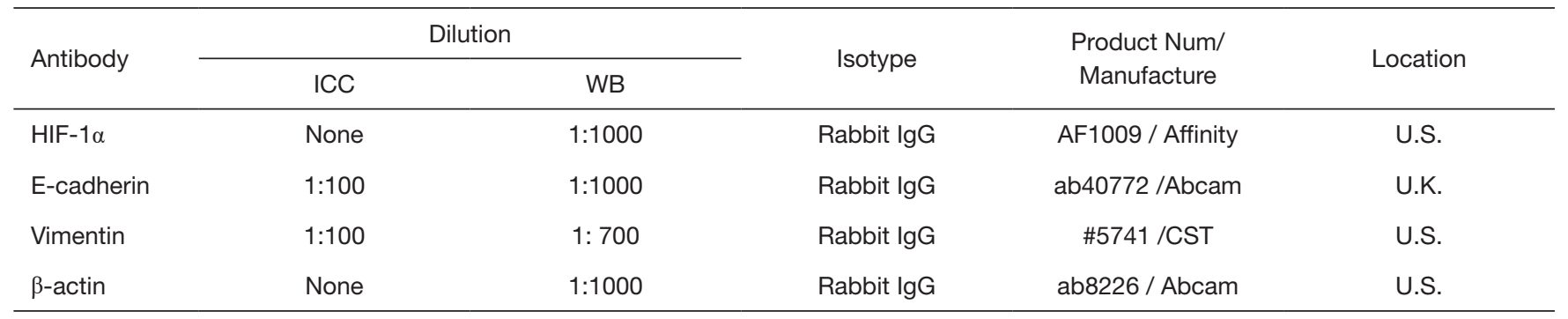

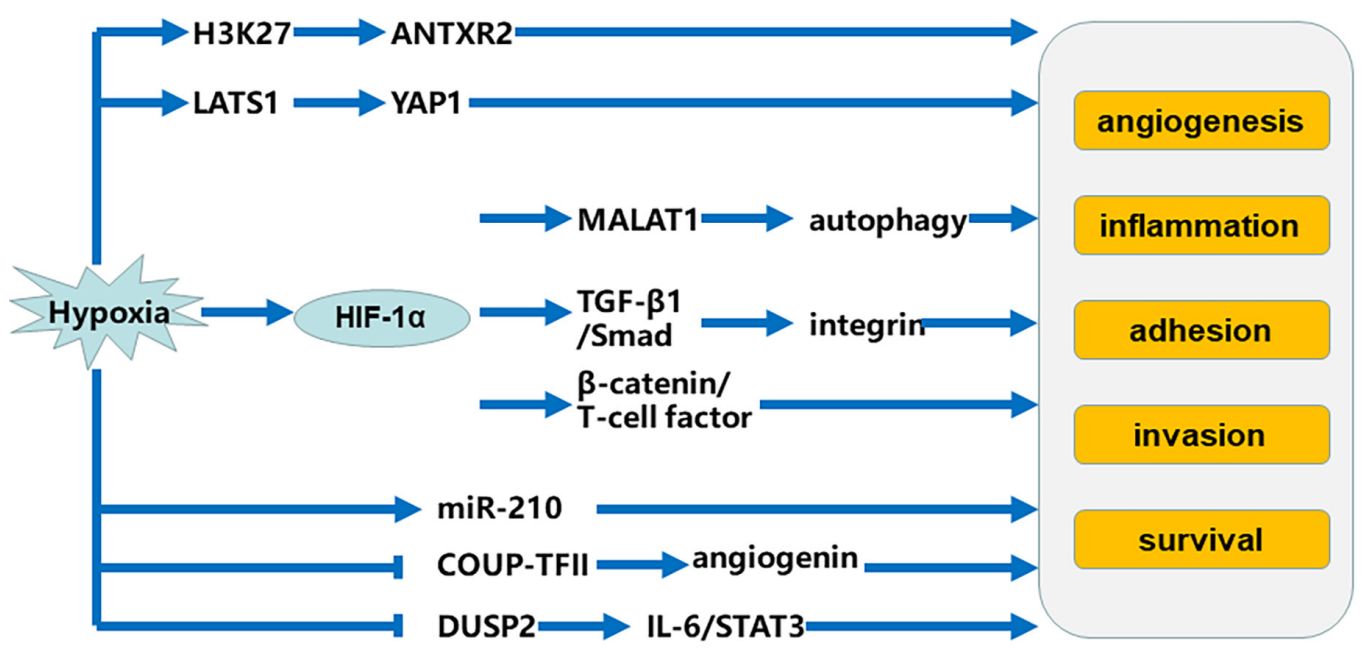

Figure S2 Hypoxia promotes the development of endometriosis through multiple mechanisms. H3K27, histone 3 lysine 27; ANTXR2, Anthrax Toxin Receptor 2; LATS1, Large Tumor Suppressor Kinase 1; YAP1, Yes-associated protein 1; HIF-1 $\alpha$, hypoxia-inducible factor-1 $\alpha$; MALAT1, Metastasis Associated in Lung Adenocarcinoma Transcript; COUP-TFII, Chicken Ovalbumin Upstream Promoter-Transcription Factor II; DUSP2, dual Specificity Phosphatase 2; IL-6, Interleukin- 6; STAT3, Signal transducer and activator of transcription 3. 